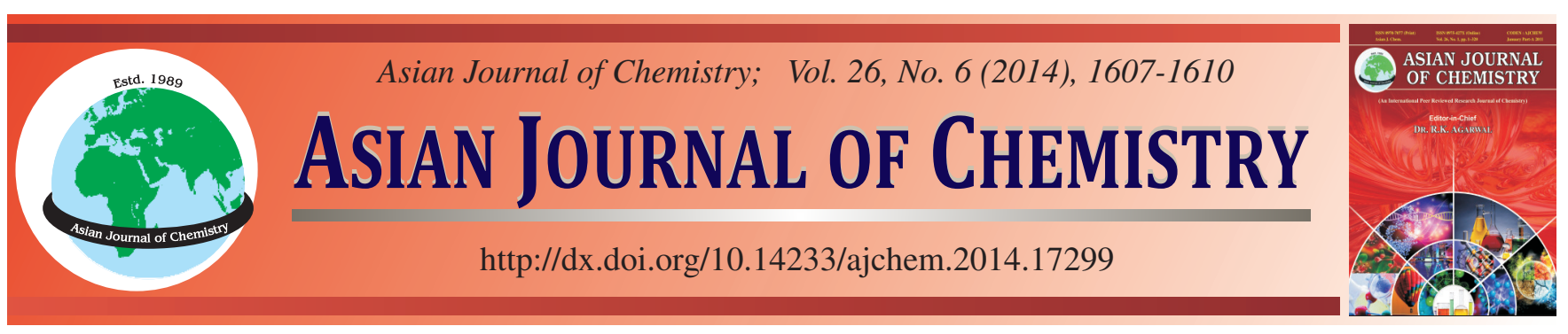

\title{
Combined Nanofibers of Carbon Nanotube, Titania and Polymer Substrate for Oxidation of Toluene and Isopropyl Alcohol $\uparrow$
}

\author{
Hyun-Jung Kang ${ }^{1}$, Seung-Ho Shin ${ }^{1}$, Ho-Hwan Chun ${ }^{2}$ and Wan-Kuen Jo ${ }^{1, *}$
}

${ }^{1}$ Department of Environmental Engineering, Kyungpook National University, Daegu 702-701, Republic of Korea

${ }^{2}$ Department of Naval Architecture and Ocean Engineering, Pusan National University, 63 Jangjeon-dong, Geumjeong-gu, Busan 609-735, Republic of Korea

*Corresponding author: Fax: +82 53 9506579; Tel: +82 53 9506584; E-mail: wkjo@knu.ac.kr

\begin{abstract}
Poly vinyl pyrrolidone (PVP)-based carbon nanotube $(\mathrm{CNT})-\mathrm{TiO}_{2}(\mathrm{PCT})$ nanofibers with different mixing ratios of polymer to $\mathrm{CNT}$ were prepared using an electrospinning method coupled to hydrothermal treatment. The photocatalytic activity of the PCT nanofibers for oxidation of an indoor concentration level of toluene and isopropyl alcohol was examined under visible-light or UV exposure conditions. In addition, photocatalytic activities of a PVP-based $\mathrm{TiO}_{2}(\mathrm{PT})$ nanofiber and $\mathrm{P}_{2} 5 \mathrm{TiO}_{2}$ were also determined for comparison with those of PCT nanofibers. The as-prepared photocatalysts were characterized using scanning electron microscopy, X-ray diffraction and diffuse reflectance UV-visible spectrophotometers. The as-prepared PCT nanofibers under visible as well as UV irradiation conditions exhibited higher photocatalytic activities as compared to two reference photocatalysts (PT nanofiber and $\mathrm{P} 25 \mathrm{TiO}_{2}$ film). Moreover, the photocatalytic oxidation efficiencies of toluene and isopropyl alcohol as determined via PCT nanofibers increased as the mixing ratios of polymer to CNT increased, suggesting that there would be the presence of an optimal ratio of polymer to CNT for the synthesis of PCT nanofibers. Overall, PCT nanofibers under visible light or UV irradiation could be effectively used for oxidation of gas-phase toluene and isopropyl alcohol.
\end{abstract}

Keywords: Base material, Polymer to carbon nanotube ratio, Composite nanofiber, Indoor air level, Photocatalytic oxidation.

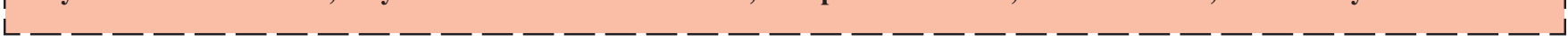

\section{INTRODUCTION}

Heterogeneous photocatalysis using an $n$-type semiconducting titania $\left(\mathrm{TiO}_{2}\right)$ is the most popularly applied technology for environmental remediation because of photocatalytic oxidation potential, excellent chemical and thermal stability and low cost ${ }^{1-3}$. However, air pollution application of $\mathrm{TiO}_{2}$ alone displays several practical drawbacks such as blowing-away problem with treated air, low adsorption ability, limited photon absorption in visible region and high recombination rate of photo-produced electron-hole pairs. The separation and blowingaway problems can be solved by immobilizing $\mathrm{TiO}_{2}$ nanoparticles to supporting materials, such as glass beads, glass tubes and polymer fibers ${ }^{4-6}$. The other three drawbacks of pure $\mathrm{TiO}_{2}$ (low adsorption ability, limited photon absorption in visible region and high recombination rate of electron-hole pairs) may be settled by combining $\mathrm{TiO}_{2}$ with carbon nanotube (CNT) (CNT-TiO ${ }_{2}$ composite). Carbon nanotubes present high adsorption capacities for environmental pollutants owing to high specific surface areas, which can enhance the photocatalytic activity of $\mathrm{TiO}_{2}$, because adsorption is an important process for the photocatalysis of environmental contaminants ${ }^{7,8}$. For CNT- $\mathrm{TiO}_{2}$ composites, photo-produced electrons generated in the space-charge separation region at the $\mathrm{CNT}_{-} \mathrm{TiO}_{2}$ boundary may be transferred into CNTs, leaving holes on the $\mathrm{TiO}_{2}$, which minimizes the recombination rates of electron-hole pairs ${ }^{9}$. As such, several studies ${ }^{10-12}$ found that $\mathrm{CNT}-\mathrm{TiO}_{2}$ composites exhibited superior photocatalytic performance compared to pure $\mathrm{TiO}_{2}$ for oxidation of environmental pollutants under visible irradiation, which was ascribed to elevated adsorption and electronic properties of $\mathrm{CNT}-\mathrm{TiO}_{2}$ composites.

Certain studies ${ }^{13,14}$ have also reported the feasibility of polymer-supported $\mathrm{TiO}_{2}$ nanofibers prepared via the electrospinning process for environmental applications. Moreover, combination of $\mathrm{CNT}, \mathrm{TiO}_{2}$ and polymer substrate to synthesize polymer-supported $\mathrm{CNT}_{-} \mathrm{TiO}_{2}$ nanofibers has been suggested as another photocatalyst that can enhance the photocatalytic performance of $\mathrm{TiO}_{2}$. This assertion was supported by previous researchers $^{5,15}$. They reported that polymer-supported CNT$\mathrm{TiO}_{2}$ nanofibers could be applied effectively for environmental

Fresented at The 7th International Conference on Multi-functional Materials and Applications, held on 22-24 November 2013, Anhui University of Science \& Technology, Huainan, Anhui Province, P.R. China 
pollutant treatment. However, they used only UV lamps as a photocatalytic light source for the oxidation of aqueous methyl orange and rhodamine $6 \mathrm{G}$, even though polymer-supported CNT-TiO ${ }_{2}$ nanofibers may also be activated under visible-light irradiation since CNTs can act as a photosensitizer, which extends photocatalysis into the visible range ${ }^{16}$. Additionally, the morphological natures of polymer nanofibers can vary with the mixing ratio of polymer to $\mathrm{CNT}^{17}$, indicating that the effect of polymer to CNT mixing ratios of polymer-supported CNT- $-\mathrm{TiO}_{2}$ nanofibers for environmental purification on their morphological characteristics, such as fiber diameter and bead structure, which can influence their photocatalytic activity, is another research topic left to be dealt with. Consequently, in the present study, polymer substrate-based $\mathrm{CNT}-\mathrm{TiO}_{2}$ nanofibers with different polymer to CNT mixing ratios were synthesized using a combined method of electrospinning and heating processes to examine the oxidation of gas-phase pollutants under visible-light as well as UV irradiation. Polyvinyl pyrrolidone (PVP) was chosen as a base polymer substrate due to its compatibility with CNTs as well as $\mathrm{TiO}_{2}$ precursors ${ }^{18,19}$. Two model gas-phase compounds, toluene and isopropyl alcohol (IPA), were chosen because of their prevalence in indoor environments ${ }^{20,21}$ and toxic effect ${ }^{22}$. In addition, toluene is one of the most investigated model gas-phase pollutant in the photocatalysis investigations ${ }^{23}$.

\section{EXPERIMENTAL}

Synthesis of photocatalysts: The PCT nanofibers were synthesized using a combined method of an electrospinning and a post-thermal treatment processes. For the synthesis of PCT nanofibers, MWCNT-COOH were first prepared by adding 2 g MWCNTs (Carbon Nano Technology Co., Korea) to 120 $\mathrm{mL} \mathrm{HNO}_{3}$ solution (Sigma-Aldrich Inc.), after which this solution was sonicated for $1 \mathrm{~h}$ for better mixing. This mixture was refluxed at $110^{\circ} \mathrm{C}$ for $20 \mathrm{~h}$ and then, filtered under vacuum through a membrane filter (0.22 millipore Teflon) to prepare MWCNT-COOH. This product was washed with distilled water, dried at $50{ }^{\circ} \mathrm{C}$ for $30 \mathrm{~h}$ under vacuum conditions. The prepared MWCNT-COOH was further combined with $\mathrm{TiO}_{2}$ fiber using the electrospinning process to synthesize PCT nanofibers. $2.5 \mathrm{~mL}$ tetra- $n$-butyl titanate (TBT, Sigma-Aldrich Inc.) was added to $2 \mathrm{~mL}$ glacial acetic acid (Sigma-Aldrich Inc.), while $0.04 \mathrm{~g}$ of MWCNT-COOH was added to $8 \mathrm{~mL}$ ethanol and then, sonicated for $3 \mathrm{~h}$. These two solutions were mixed and stirred for $0.5 \mathrm{~h}$. Subsequently, this mixture was added to 0.53, 0.77, 1.22, 1.58 and 2.35 g PVP (MW 1,300,000, Sigma-Aldrich Inc.) dispersed in $6 \mathrm{~mL}$ ethanol (Sigma-Aldrich Inc.). This solution was stirred for $3 \mathrm{~h}$ to obtain homogeneous dark ink-like suspension. The final solution was loaded into a glass syringe, which was placed $15 \mathrm{~cm}$ above a piece of aluminum foil. A DC voltage of $18 \mathrm{kV}$ was supplied. The electrospun PCT nanofibers were conditioned at $80{ }^{\circ} \mathrm{C}$ for $12 \mathrm{~h}$ under vacuum conditions. The final products prepared using PVP of $0.53,0.77,1.22,1.58$ and $2.35 \mathrm{~g}$ were labeled as PCT-13, PCT19, PCT-30, PCT-39 and PCT-58, respectively.

The characteristics of as-prepared PCT samples were examined using scanning electron microscopy (SEM), X-ray diffraction (XRD) meter and UV-visible spectroscopy. SEM images were examined by Hitachi FE-SEM S-4300 and energy-dispersive X-ray (EDX)-350 at an acceleration voltage of $15 \mathrm{kV}$. XRD patterns were determined using a Rigaku D/ max-2500 diffractometer in the range of $20-80^{\circ}$. UV-visible absorption spectra were determined using a Varian CARY 5G spectrophotometer.

Photocatalysis tests: The photocatalytic activity of asprepared PCT nanofibers were investigated for the oxidation of toluene and isopropyl alcohol using a continuous-flow Pyrex reactor with a size of $25 \mathrm{~cm}$ length and $4.5 \mathrm{~cm}$ inside diameter. The inner-wall of the Pyrex reactor was coated with PCT nanofiber. A cylindrical-shaped lamp was inserted inside the Pyrex reactor and served as the inner surface of this reactor. The UV light was provided by a fluorescent black light lamp (8W, Youngwha Lamp Co. F8T5/BLB), while visible-light was provided by a fluorescent daylight lamp (8W, Youngwha Lamp Co. F8T5DL). Standard gas with $0.1 \mathrm{ppm}$ for each compound was prepared by adjusting the mixing ratio of standard solutions injected into a Pyrex bulb at a constant rate via a syringe pump (model 210, KdScientific Inc.) and airstream flow rate (AFR). Airstream flow rate was measured using mass flow controllers and fixed to $2.0 \mathrm{~L} \mathrm{~min}^{-1}$. The humidity levels were controlled at $\mathrm{ca} .90 \%$. Air sampling was carried out periodically at the upstream and downstream portions of Pyrex reactor by filling a $5 \mathrm{~L}$ Tedlar bag at a constant flow rate for 5-10 min. Air from the Tedlar bag was then drawn through a adsorbent trap containing $0.3 \mathrm{~g}$ Tenax TA using a constant flow sampler (Aircheck Sampler Model 224-PCXR8, SKC). The target compounds collected on the sorbent trap were analyzed using an automated thermal desorber (Perkin Elmer ATD 350)-gas chromatography (GC, Perkin Elmer Clarus 680)/mass spectrometer (MS, Perkin Elmer Clarus SQ8 T) system. Identification of each compound was accomplished using its retention time and mass spectra (Wiley 275 software library).

\section{RESULTS AND DISCUSSION}

Surface properties of as-prepared photocatalysts: The characteristics of the as-prepared $\mathrm{TiO}_{2}$ photocatalysts (PCT13, PCT-19, PCT-30, PCT-39 and PCT-58) were investigated using SEM, XRD and UV-visible spectroscopy. Fig. 1 represents the SEM images of the composite PCTs with different polymer to CNT mixing ratios. The SEM results indicated that the nanofibers could successfully be formed, when the combined method of an electrospinning and a post-thermal treatment processes was applied. Hu et al. ${ }^{15}$ also reported that polymer-based $\mathrm{TiO}_{2} / \mathrm{CNT}$ nanotubes nanofibers could be produced using a sol-gel method followed by an electrospinning process. The diameter of PCTs increased as the polymer to CNT mixing ratios increased due to the addition of more polymer for PCTs with high polymer to CNT mixing ratios.

The UV-visible spectra of the as-prepared PCTs with different MWCNT to $\mathrm{TiO}_{2}$ mixing ratios, $\mathrm{PT}$ and $\mathrm{P} 25 \mathrm{TiO}_{2}$ also studied. The PCTs displayed stronger light absorption intensity in visible range compared to the PT, which exhibited, in turn, stronger light intensity relative to $\mathrm{P} 25 \mathrm{TiO}_{2}$. However, the visible-light absorption intensity of PCTs did not depend on the MWCNT to $\mathrm{TiO}_{2}$ mixing ratios. Meanwhile, other studies ${ }^{4,25,26}$ reported that $\mathrm{P} 25 \mathrm{TiO}_{2}$ displayed an absorption edge 


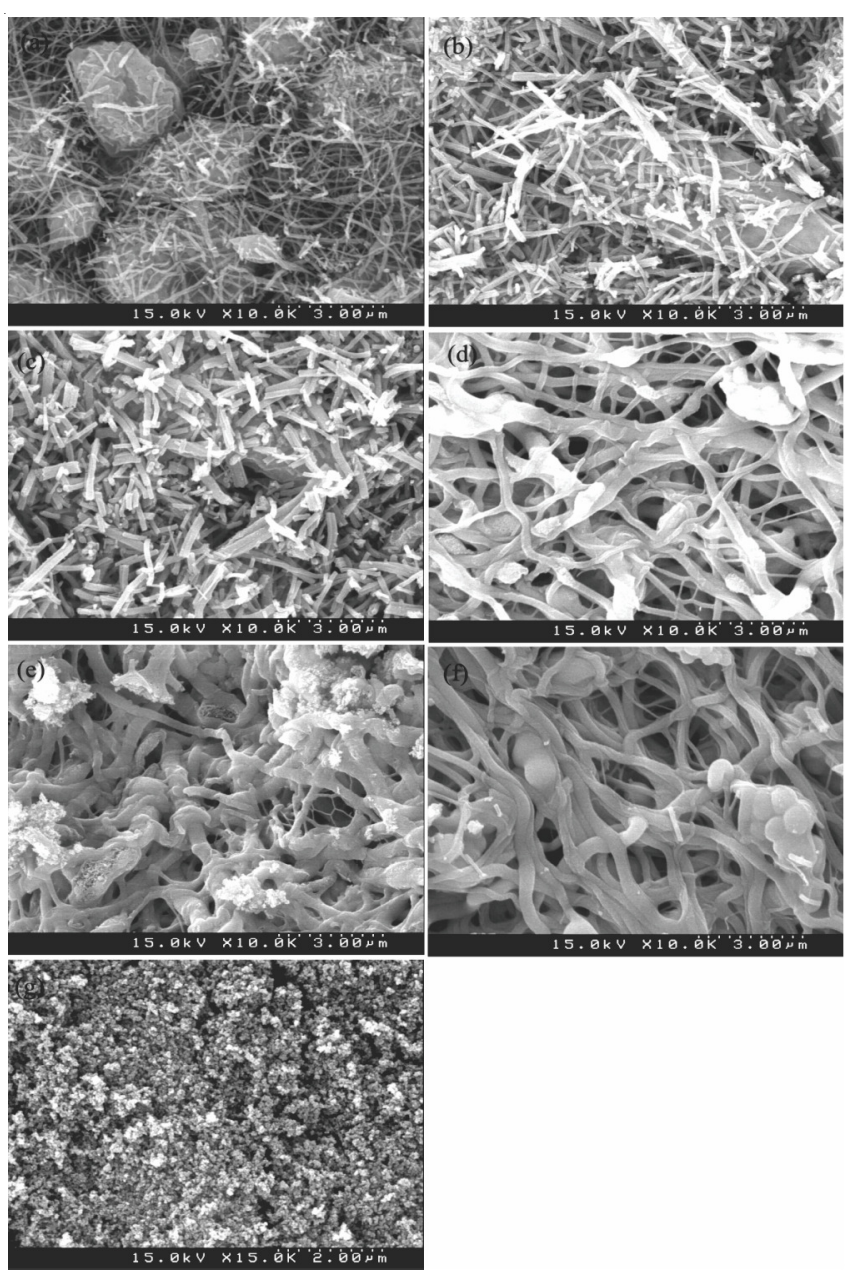

Fig. 1. Scanning electron microscopy images of PCT-13, PCT-19, PCT30, PCT-39, PCT-58 and PT nanofibers and P25 $\mathrm{TiO}_{2}$

in UV range around $420 \mathrm{~nm}$. In contrast, the absorption edge of the PCTs shifted well to the visible-light range. This absorption shift was assigned to the presence of carbon species at interstitial positions of $\mathrm{TiO}_{2}$ lattice ${ }^{15}$. Consequently, these results suggested that the as-prepared PCTs could be activated under visible-light as well as UV irradiation.

Photocatalytic oxidation of toluene and isopropyl alcohol: As-prepared PCT nanofibers with different polymer to CNT mixing ratios (PCT-13, PCT-19, PCT-30, PCT-39, PCT58), which were synthesized using an electrospinning

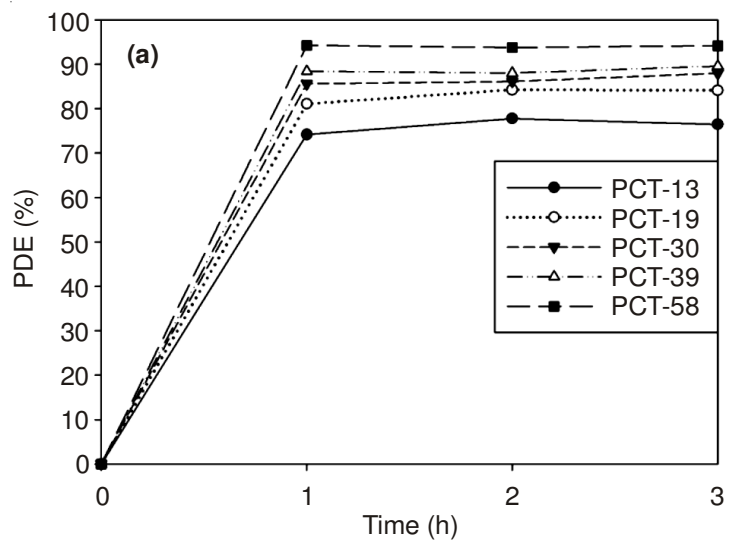

technique coupled to heating processes were examined for the oxidation of toluene and isopropyl alcohol under UV or visiblelight exposure. Fig. 2 shows that the photocatalytic oxidation efficiencies of toluene and isopropyl alcohol as determined via PCT nanofibers increased as the mixing ratios of polymer to CNT increased. Specifically, the average photocatalytic oxidation efficiencies of toluene and isopropyl alcohol obtained from PCT-13 were 73 and $94 \%$, respectively, while those obtained from the PCT-58 were 96 and close to $100 \%$, respectively. These data were obtained at the condition of a stream flow rate of $2 \mathrm{~L} \mathrm{~min}^{-1}$, because the photocatalytic oxidations were too high (close to $100 \%$ ) to be distingushable at the condition of a stream flow rate of $1 \mathrm{~L} \mathrm{~min}^{-1}$. The results implied that there would be the presence of an optimal ratio of polymer to CNT for the synthesis of PCT nanofibers. Overall, PCT nanofibers could be better utilized for photocatalytic oxidation of gas-phase indoor toluene and isopropyl alcohol, when optimal ratios of polymer to CNT were used for the preparation of PCT nanofibers.

Fig. 3 displays the time-series photocatalytic oxidation efficiencies of toluene and isopropyl alcohol obtained from the as-prepared PCT nanofibers (PCT-13, PCT-19, PCT-30, PCT-39, PCT-58) under visible-light irradiation. These data were also obtained at the condition of a stream flow rate of $2 \mathrm{~L} \mathrm{~min}^{-1}$, because the photocatalytic oxidations were too high to be distingushable at the condition of a stream flow rate of $1 \mathrm{~L} \mathrm{~min}^{-1}$. Similar to the UV irradiation conditions, the photocatlytic oxidation efficiencies of toluene and isopropyl alcohol under visible-light irradiation increased as the mixing ratios of polymer to CNT increased. Specifically, the average photocatalytic oxidation efficiencies of toluene and isopropyl alcohol obtained from PCT-13 were 15 and $63 \%$, respectively, while those obtained from the PCT-58 were 28 and $82 \%$, respectively.

\section{Conclusion}

In this study, the application of PCT nanofibers with different weight ratios of polymet to CNT were prepared using an electrospinning technique for the photocatalytic oxidation of two important indoor pollutants (toluene and isopropyl alcohol). The as-prepared PCT and PT nanofibers and P25 $\mathrm{TiO}_{2}$ were sucessufully characterized using SEM, XRD and UV-visible spectrophotometers. It was found that PCT nanofibers

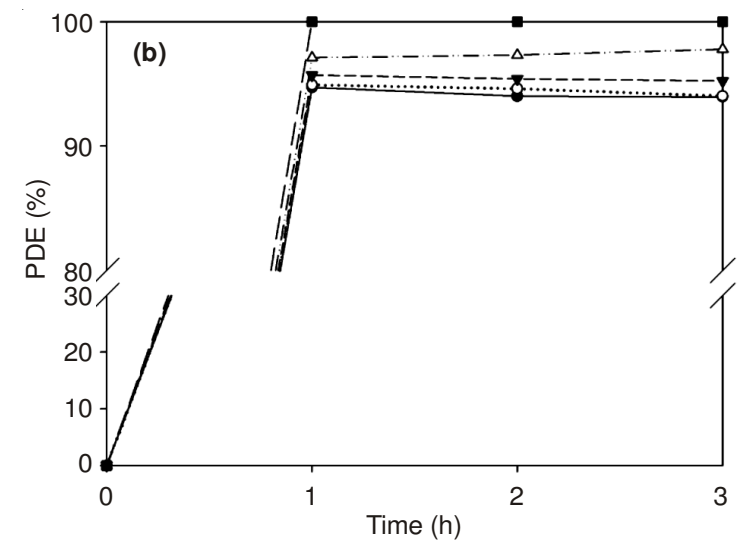

Fig. 2. Time-series photocatalytic oxidation efficiencies (PDEs, \%) of (a) toluene and (b) isopropyl alcohol as determined via PCT-13, PCT-19, PCT-30, PCT-39 and PCT-58 photocatalysts under UV irradiation. Stream flow rate was fixed to $2 \mathrm{~L} \mathrm{~min}^{-1}$ 

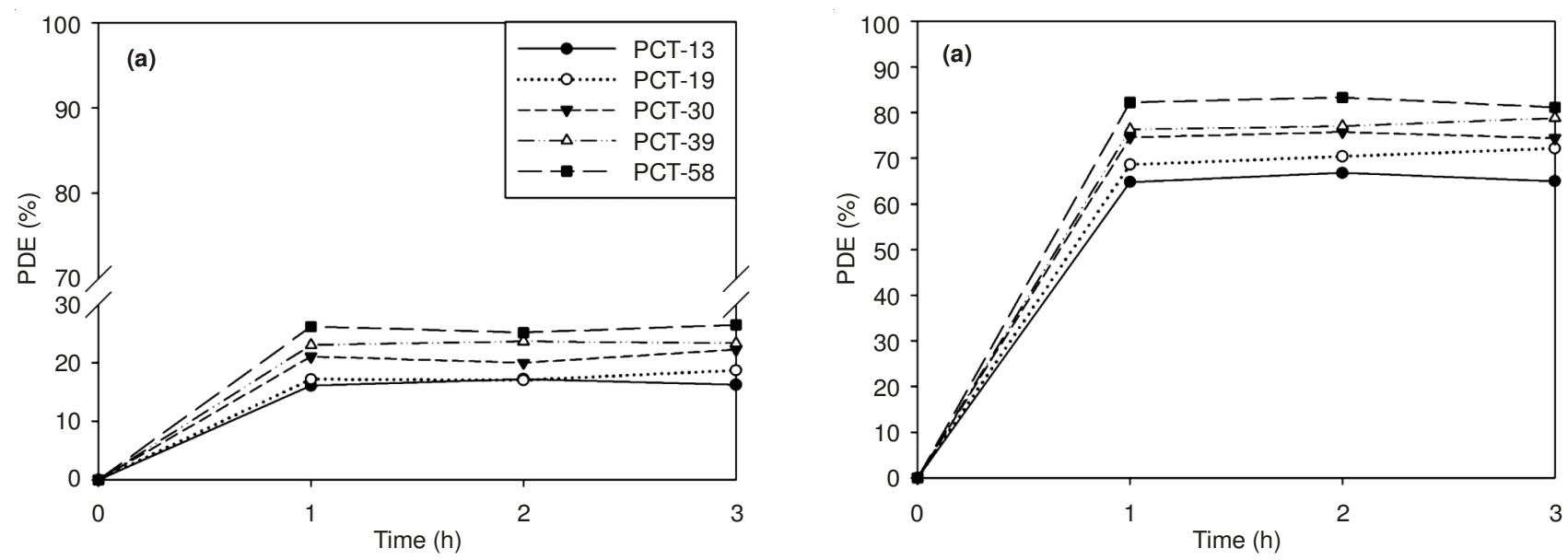

Fig. 3. Time-series photocatalytic oxidation efficiencies (PDEs, \%) of (a) toluene and (b) isopropyl alcohol as determined via PCT-13, PCT-19, PCT-30, PCT-39 and PCT-58 photocatalysts under visible-light irradiation. Stream flow rate was fixed to $2 \mathrm{~L} \mathrm{~min}^{-1}$

under visible-light as well as UV irradition had higher photocatalytic activity than PT nanofiber or $\mathrm{P} 25 \mathrm{TiO}_{2}$ photocatalyst for oxidation of the gas-phase target polltants. Another major finding was that the photocatalytic oxidation efficiencies of toluene and isopropyl alcohol as determined via PCT nanofibers increased as the mixing ratios of polymer to CNT increased. Taken together, PCT nanofibers could be employed effectively for the photocatalytic oxidation of indoor concentration levels of toluene and isopropyl alcohol under UV or visible-light exposure conditions.

\section{ACKNOWLEDGEMENTS}

This work was supported by the National Research Foundation of Korea (NRF) grant funded by the Korean Government (No. 2011-0027916) and through GCRC-SOP (No. 2011-0030013).

\section{REFERENCES}

1. $\quad$ U.I. Gaya and A.H. Abdullah, J. Photochem. Photobiol. Chem., 9, 1 (2008).

2. K. Nakata and A. Fujishima, J. Photochem. Photobiol. Chem., 13, 169 (2012)

3. T. Ochiai and A. Fujishima, J. Photochem. Photobiol. Chem., 13, 247 (2012).

4. W.K. Jo and J.T. Kim, J. Hazard. Mater., 164, 360 (2009).

5. S. Kedem, D. Rozen, Y. Cohen and Y. Paz, J. Phys. Chem. C, 113, 14893 (2009).

6. S.W. Verbruggen, S. Ribbens, T. Tytgat, B. Hauchecorne, M. Smits, V. Meynen, P. Cool, J.A. Martens and S. Lenaerts, Chem. Eng. J., 174, 318 (2011).
7. K. Woan, G. Pyrgiotakis and W. Sigmund, Adv. Mater., 21, 2233 (2009).

8. P. Serp, M. Corrias and P. Kalck, Appl. Catal. A, 253, 337 (2003).

9. R. Leary and A. Westwood, Carbon, 49, 741 (2011).

10. W. Wang, P. Serp, P. Kalck, C.G. Silva and J.L. Faria, Mater. Res. Bull., 43, 958 (2008)

11. Y. Yao, G. Li, S. Ciston, R.M. Lueptow and K.A. Gray, Environ. Sci. Technol., 42, 4952 (2008).

12. C.-Y. Yen, Y.-F. Lin, C.-H. Hung, Y.-H. Tseng, C.-C. Ma, M.-C. Chang and H. Shao, Nanotechnology, 19, 045604 (2008).

13. A.K. Alves, F.A. Berutti, F.J. Clemens, T. Graule and C.P. Bergmann, Mater. Res. Bull., 44, 312 (2009).

14. X. Zhang, S. Xu and G. Han, Mater. Lett., 63, 1761 (2009).

15. G. Hu, X. Meng, X. Feng, Y. Ding, S. Zhang and M. Yang, J. Mater. Sci., 42, 7162 (2007).

16. Y. Ou, J. Lin, S. Fang and D. Liao, Chem. Phys. Lett., 429, 199 (2006).

17. M.K. Pilehrood, P. Heikkilä and A. Harlin, Autex Res. J., 12, 1 (2012).

18. M.J. O'Connell, P. Boul, L.M. Ericson, C. Huffman, Y. Wang, E. Haroz, C. Kuper, J. Tour, K.D. Ausman and R.E. Smalley, Chem. Phys. Lett., 342, 265 (2001).

19. D. Li and Y. Xia, Nano Lett., 3, 555 (2003).

20. E. Uhde and T. Salthammer, Atmos. Environ., 41, 3111 (2007).

21. S.H. Shin and W.K. Jo, Chemosphere, 89, 569 (2012).

22. IARC (International Agency for Research on Cancer), Monographs on the evaluation of the carcinogenic risks of chemicals to man. WHO, Geneva (2004).

23. AFNOR, XP-B44-013 Standard, in Photocatalysis: Test \& Analysis Method for Determining the Efficiency of Photocatalytic Systems for Eliminating VOC/Odours in Recirculating Indoor Air - Confined Chamber Test (2009).

24. B. Krishnakumar and M. Swaminathan, J. Mol. Catal. A, 350, 16 (2011).

25. N.T. Nolan, D.W. Synnott, M.K. Seery, S.J. Hinder, Van Wassenhoven and S.C. Pillai, J. Hazard. Mater, 211-212, 88 (2012).

26. S. Chainarong, L. Sikong, S. Pavasupree and S. Niyomwas, Energy Procedia, 9, 418 (2011). 